\title{
Pulse Oximetry Overestimates Oxygen Saturation in COPD
}

\author{
Sridhar Amalakanti MD and Mohan Rao Pentakota MD
}

\begin{abstract}
BACKGROUND: Measurement of oxygen saturation with a handheld pulse oximeter is widely practiced as a surrogate to invasive arterial blood gas analysis. Oxygen saturation is an important parameter in cases of COPD, but there are insufficient data on the role of pulse oximetry in patients with COPD, moreso in diseases across its spectrum, such as chronic bronchitis and emphysema. We assessed the performance of pulse oximetry in acute respiratory failure of patients with COPD. METHODS: This was a cross-sectional, observational study. We studied 50 subjects with COPD admitted to the Government General Hospital, a 1,000-bed tertiary referral center in Guntur, India, from June 2013 to July 2013. Simultaneous reading of $\mathrm{S}_{\mathrm{pO}_{2}}$ by a handheld pulse oximeter and $\mathrm{S}_{\mathrm{aO}}$ by an automated arterial blood gas analyzer were taken. RESULTS: Pulse oximetry was sufficiently sensitive $(\mathbf{8 4 . 6 0 \%})$ to hypoxemia in respiratory failure to be used in clinical situations. The mean difference (bias) between $\mathrm{S}_{\mathrm{aO}_{2}}$ and $\mathrm{S}_{\mathrm{pO}_{2}}$ was -3.98 (95\% CI -4.68 to 3.28). There was less sensitivity $(82 \%$ vs $85 \%)$ and positive predictive value $(69 \%$ vs $85 \%)$ of the pulse oximeter to respiratory failure in subjects with chronic bronchitis versus emphysema. CONCLUSIONS: Pulse oximetry performed poorly in comparison with the invasive arterial blood gas analysis. The variability of the readings was greater in the subjects with chronic bronchitis than in those with emphysema. Key words: blood gas analysis; transcutaneous blood gas monitoring; oximetry; COPD; chronic bronchitis; emphysema. [Respir Care 2016;61(4):423-427. (C) 2016 Daedalus Enterprises]
\end{abstract}

\section{Introduction}

COPD is a relentlessly progressive debilitating disease, punctuated by exacerbations of acute respiratory failure. These episodes of acute respiratory failure can be diagnosed by measuring the oxygen saturation of hemoglobin in the blood. Obtaining accurate data regarding the oxygenation saturation of hemoglobin in blood $\left(\mathrm{S}_{\mathrm{aO}}\right)$ requires invasive arterial blood gas ( $\mathrm{ABG}$ ) analysis. Noninvasive measurement of arterial $\mathrm{S}_{\mathrm{pO}_{2}}$ is obtained by an instrument called a pulse oximeter. Pulse oximetry has become a standard practice in monitoring oxygen levels in the pa-

Dr Amalakanti is affiliated with the Department of Neurology, and Dr Pentakota is affiliated with the Department of General Medicine, Guntur Medical College, Guntur, India.

The authors have disclosed no conflicts of interest.

Correspondence: Amalakanti Sridhar MD, Department of Neurology, Government General Hospital, Guntur 522002, India. E-mail: iamimenotu@gmail.com.

DOI: $10.4187 /$ respcare. 04435 tient's blood. Studies on the performance of pulse oximetry show that: (1) there is a very strong correlation $(\mathrm{r}=0.91)$ of $\mathrm{S}_{\mathrm{aO}}$ readings with $\mathrm{S}_{\mathrm{pO}_{2}}$ values ${ }^{1}$ but only moderate correlation between the degree of change; (2) the pulse oximeter overestimates actual changes in $\mathrm{S}_{\mathrm{aO}_{2}}{ }^{2,3}$; and (3) high $\mathrm{S}_{\mathrm{pO}_{2}}$ thresholds are necessary to detect significant hypoxemia with pulse oximetry. ${ }^{4}$ However, the data were gathered from studies in subjects with shock and ARDS. We performed a prospective observational study to assess the performance of handheld pulse oximetry in predicting hypoxemia in subjects with an exacerbation of COPD and to compare the efficacy of handheld pulse oximetry in the diagnosis of hypoxemia in chronic bronchitis and emphysema.

\section{Methods}

Fifty consecutive subjects diagnosed with COPD with acute respiratory failure attending the Department of General Medicine, Government General Hospital, a 1,000-bed tertiary hospital in Guntur, India, over a period of 1 month were enrolled into the study. Patients with icterus, other 


\section{Pulse Oximetry Overestimates Oxygen Saturation in COPD}

respiratory disorders, and other systemic disorders compromising or altering respiratory function were excluded.

The diagnosis of COPD was considered following the Global Initiative for Chronic Obstructive Lung Disease (GOLD) 2013 guidelines. ${ }^{5}$ Subjects with dyspnea, chronic cough, and/or sputum production and a history of exposure to risk factors and a post-bronchodilator $\mathrm{FEV}_{1} / \mathrm{FVC}$ of $<0.70$ on spirometry were included in the study.

Subjects with a chronic productive cough for 3 months in each of 2 successive years in whom other causes of productive chronic cough were excluded were diagnosed with predominantly chronic bronchitis. ${ }^{6}$ Subjects were diagnosed with predominantly emphysema based on established guidelines for clinical, radiographic, and spirometry analysis. $^{7}$

Subjects were diagnosed with respiratory failure when $\geq 2$ of the following criteria ${ }^{8}$ were met: (1) acute respiratory distress, including severe dyspnea at rest and a breathing frequency of $>35$ breaths/min and/or active contraction of the accessory muscles of respiration or paradoxical abdominal motion; (2) hypercapnia $\left(\mathrm{P}_{\mathrm{aCO}_{2}}>50 \mathrm{~mm} \mathrm{Hg}\right)$ with respiratory acidosis ( $\mathrm{pH}<7.33$ ); and (3) hypoxemia $\left(\mathrm{S}_{\mathrm{aO}_{2}}<90 \%\right)$.

Pulse oximetry was used to measure $\mathrm{S}_{\mathrm{pO}_{2}}$ in these COPD candidates using a Nellcor N-200 (Nellcor, Hayward, California) co-oximeter finger probe in a sitting position. A single pulse oximeter was used for all subjects. After 1 min of a stable $\mathrm{S}_{\mathrm{pO}_{2}}$ reading, a simultaneous $\mathrm{ABG}$ reading was obtained from the radial artery for $\mathrm{ABG}$ analysis. One single reading of $\mathrm{S}_{\mathrm{pO}_{2}}$ by pulse oximeter and its corresponding simultaneous $\mathrm{S}_{\mathrm{aO}}$, were obtained per subject. ABG analyzer CO-oximetry measurements included oxyhemoglobin saturation $\left(\mathrm{S}_{\mathrm{aO}_{2}}\right)$, carboxyhemoglobin, $\mathrm{P}_{\mathrm{aO}}$, $\mathrm{P}_{\mathrm{aCO}}$, and $\mathrm{pH}$ (ABL-520 blood gas analyzer, Radiometer, Copenhagen, Denmark). The study protocol conformed to the ethical guidelines for biomedical research on human participants of the Indian Council of Medical Research ${ }^{9}$ and was approved by the institutional ethical committee at Guntur Medical College.

\section{Statistical Analysis}

Data were analyzed using Microsoft Excel 2007. The agreement between measurements of $\mathrm{S}_{\mathrm{pO}_{2}}$ and $\mathrm{S}_{\mathrm{aO}_{2}}$ in all subjects was analyzed using a Bland-Altman plot, in which the difference between $\mathrm{S}_{\mathrm{pO}_{2}}$ and $\mathrm{S}_{\mathrm{aO}_{2}}$ was plotted against their average. ${ }^{10}$ Bias was calculated as the mean of the differences between the ABG analyzer and pulse oximeter readings $\left(\mathrm{S}_{\mathrm{aO}_{2}}-\mathrm{S}_{\mathrm{pO}_{2}}\right)$. Positive bias indicated that the pulse oximeter underestimated the $\mathrm{S}_{\mathrm{aO}}$, whereas negative bias indicated that the pulse oximeter was overestimating the $\mathrm{S}_{\mathrm{aO}_{2}}$. The limits of agreement were taken as the bias \pm $(1.96 \times \mathrm{SD})$.

\section{QUICK LOOK}

\section{Current knowledge}

Handheld pulse oximeters are used in routine clinical practice to measure oxygen saturation of the blood. They are noninvasive and easy to use. However, studies in subjects with shock and ARDS show that these instruments are reliable only at high blood oxygen saturation levels.

\section{What this paper contributes to our knowledge}

The handheld pulse oximeter was not reliable in diagnosing respiratory failure on its own. It overestimated the oxygen saturation of blood in subjects with COPD. The variability of the pulse oximeter readings was greater in subjects with chronic bronchitis than in those with emphysema.

\section{Results}

During the study period, 78 patients were admitted with COPD. Fifty subjects (41 males and 9 females) were enrolled in the study. Those excluded had associated pneumonitis $(n=8)$, bronchiectasis $(n=3)$, chronic kidney disease $(n=6)$, and heart failure $(n=11)$. The mean age of the subjects was $63 \pm 13 \mathrm{y}$. Twenty-seven subjects were diagnosed with predominant chronic bronchitis, and 23 were diagnosed with predominant emphysema. Table 1 shows the data summary. Bland-Altman analysis is shown in Figure 1 and Table 2 and shows consistent overestimation (mean bias $=-3.9$ ) of arterial oxygen saturation by pulse oximetry. Positive predictive value is $88 \%$ for COPD, $85 \%$ for emphysema, and only $69 \%$ in chronic bronchitis (Table 3).

\section{Discussion}

The mean age (63 y) distribution of the subjects reflects the progressive respiratory insufficiency in COPD, which debilitates patients late in its natural history. The preponderance of male population could be attributed to the habit of smoking and also to significant exposure to pollutants outside of the house, both of these characteristics being more common to men. The studied subjects have largely been laborers in whom the exposure to air pollution might be contributory to their respiratory ailments.

Considering the agreement limits ( -4.68 to 3.28$)$, the handheld pulse oximeter performs poorly in acute respiratory failure in COPD as a whole. However, it can be used to aid in pointing out the trend of rise or fall in blood oxygen saturation. 


\section{Pulse Oximetry Overestimates Oxygen Saturation in COPD}

Table 1. Blood Gas Measurements in the Subgroups of Subjects With COPD

\begin{tabular}{lcccc}
\hline \hline \multicolumn{1}{c}{ Characteristic } & COPD $(N=50)$ & Chronic Bronchitis $(n=27)$ & Emphysema $(n=23)$ & Hypoxia $(n=23)$ \\
\hline $\mathrm{S}_{\mathrm{aO}_{2}}$, mean $\pm \mathrm{SD} \%$ & $83 \pm 14$ & $83 \pm 15$ & $83 \pm 14$ & $71 \pm 12$ \\
$\mathrm{~S}_{\mathrm{pO}_{2}}$, mean $\pm \mathrm{SD} \%$ & $87 \pm 10$ & $87 \pm 10$ & $88 \pm 10$ & $79 \pm 11$ \\
$\mathrm{P}_{\mathrm{aO}_{2}}$, mean $\pm \mathrm{SD} \mathrm{mm} \mathrm{Hg}$ & $63 \pm 18$ & $65 \pm 18$ & $61 \pm 18$ & $51 \pm 15$ \\
$\mathrm{P}_{\mathrm{aCO}}$, mean $\pm \mathrm{SD} \mathrm{mm} \mathrm{Hg}$ & $67 \pm 12$ & $68 \pm 12$ & $65 \pm 12$ & $64 \pm 8$ \\
\hline
\end{tabular}
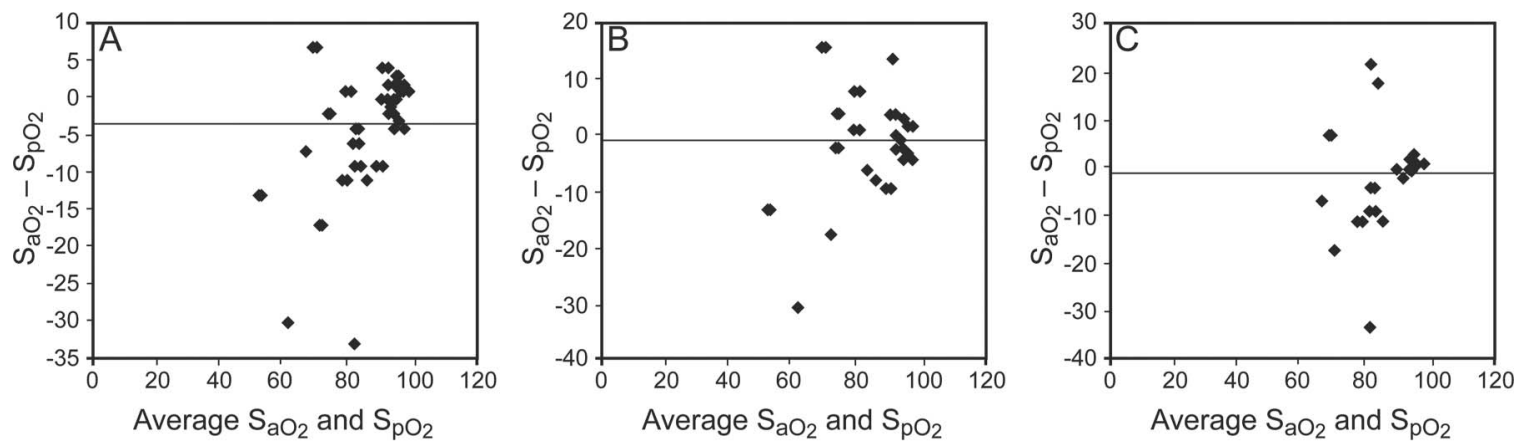

Fig. 1. Bland-Altman plots for agreements between arterial blood gas analysis and pulse oximeter measurements in subjects with COPD $(A)$, subjects with chronic bronchitis $(B)$, and subjects with emphysema (C). Horizontal lines denote the mean differences.

Table 2. Bland-Altman Agreement Analysis

\begin{tabular}{lcc}
\hline \hline \multicolumn{1}{c}{ Diagnosis } & Mean Difference (Bias) & 95\% CI \\
\hline COPD & -3.9 & -4.68 to 3.28 \\
Chronic bronchitis & -3.0 & -2.25 to 3.81 \\
Emphysema & -2.4 & -1.85 to 3.09 \\
\hline
\end{tabular}

The Bland-Altman plot (Fig. 1) shows some degree of difference between $\mathrm{S}_{\mathrm{aO}_{2}}$ and $\mathrm{S}_{\mathrm{pO}_{2}}$. With the mean difference (bias) being -3.98 (95\% CI -4.68 to 3.28 ), the pulse oximeter consistently overestimates oxygen saturation. In COPD, this error may severely affect the treatment decisions in borderline cases.

In patients with COPD, the right-ventricular end-diastolic pressures are increased. The interventricular septum is pushed toward the left ventricle and compromises its function. ${ }^{11}$ The arterial pulse dependent on left-ventricular contraction is thus altered, and faulty values may be seen in pulse oximetry. The amount of oxygen delivered to the patient with COPD has to be finely tuned, since both hypoxia and hyperoxgenation are known to increase the death rates in patients with COPD. ${ }^{12}$ Hence, respiratory therapy based solely on pulse oximetry is ill-advised in patients with COPD.

Therefore, pulse oximetry should be interpreted in the light of other clinical features of respiratory failure pending $\mathrm{ABG}$ analysis. Different studies show a wide range $(-0.02$ to 3.39$)$ of bias between the oxygen saturation assessed by pulse oximetry and arterial blood gas analysis (Table 4)..$^{2-4,13-16}$
This may in part be due to the different clinical situations in which the studies were performed and the fact that the pulse oximeter interprets the ratio of oxyhemoglobin to total hemoglobin in the pulsatile arterial vessels. ${ }^{17}$ Therefore, factors altering the detection of pulsatility of the arteries limit the accuracy of the $\mathrm{S}_{\mathrm{pO}_{2}}$ values. It is known to be unreliable in low perfusion states, dyshemoglobinemia, hypothermia, carbon monoxide, icterus, and anemia. ${ }^{18}$ It appears to be a reliable tool in conditions such as cyanotic congenital heart disease, ${ }^{15}$ where there is less direct dysregulation of the peripheral vasculature than in conditions like liver transplantation ${ }^{3}$ and systemic sclerosis. ${ }^{14}$

These observations should be kept in mind by the clinician when interpreting pulse oximetry in an emergency setting. In short, the disease itself has a bearing on the accuracy of the instrument.

When the data were analyzed under subclasses of chronic bronchitis and emphysema, the Bland-Altman analysis (Table 2) showed higher variation of agreement limits in subjects with chronic bronchitis than in emphysema. The sensitivity of the pulse oximeter to respiratory failure in subjects with chronic bronchitis $(81 \%)$ (Table 3) was less than that noted in those with emphysema $(85 \%)$. Adding to this the low specificity $(75 \%)$ of pulse oximetry in chronic bronchitis makes it doubly inefficient. Its readings in chronic bronchitis may fail to show hypoxemia when it is present (low sensitivity), and they may show erroneously low values in the absence of hypoxia (low specificity). This may be due to the fact that hemodynamic instability is generally greater 


\section{Pulse Oximetry Overestimates Oxygen Saturation in COPD}

Table 3. Performance Characteristics of Handheld Pulse Oximetry

\begin{tabular}{lcrr}
\hline \hline \multicolumn{1}{c}{ Characteristic } & COPD (95\% CI) & Chronic Bronchitis (95\% CI) & Emphysema (95\% CI) \\
\hline Sensitivity, \% & $84.6(64.2-94.9)$ & $81.8(47.7-96.7)$ & $84.6(53.6-97.2)$ \\
Specificity, \% & $87.5(66.5-96.7)$ & $75(47.4-91.6)$ & $80(44.2-96.4)$ \\
Positive predictive value, \% & $88(67.6-96.8)$ & $69(38.8-89.6)$ & $85(53.6-97.2)$ \\
Negative predictive value, $\%$ & $84(63-94.7)$ & $86(56.1-97.4)$ & $80(44.2-96.4)$ \\
\hline
\end{tabular}

Table 4. Comparative Studies of Arterial Blood Gas Analysis and Pulse Oximetry

\begin{tabular}{|c|c|c|c|c|c|c|c|c|}
\hline Parameter & $\begin{array}{l}\text { Present } \\
\text { Study }\end{array}$ & $\begin{array}{l}\text { Nesseler } \\
\text { et } \mathrm{al}^{13}\end{array}$ & $\begin{array}{l}\text { Swigris } \\
\text { et } \mathrm{al}^{14}\end{array}$ & $\begin{array}{l}\text { Perkins } \\
\text { et } \mathrm{al}^{2}\end{array}$ & $\begin{array}{l}\text { Abrams } \\
\text { et } \mathrm{al}^{3}\end{array}$ & $\begin{array}{c}\text { Van de Louw } \\
\text { et } \mathrm{al}^{4}\end{array}$ & $\begin{array}{l}\text { Tachibana } \\
\text { et } \mathrm{al}^{15}\end{array}$ & $\begin{array}{l}\text { Ibáñez } \\
\text { et al }{ }^{16}\end{array}$ \\
\hline Subjects, $n$ & 50 & 32 & 83 & 22 & 200 & 102 & 90 & 24 \\
\hline Bias & 3.39 & 1.4 & 2.98 & 1.34 & 3.37 & 0.02 & 1.7 & 2.49 \\
\hline Agreement limits & -4.68 to 3.28 & -8 to 10.9 & & -2.29 to 4.7 & & & & \\
\hline
\end{tabular}

in patients with chronic bronchitis than in those with emphysema, which may cause fluctuations in recording $\mathrm{S}_{\mathrm{pO}_{2}}$. The distinct pathophysiologies ${ }^{19}$ of these 2 disorders contribute to the differential findings.

In chronic bronchitis, cough and sputum production usually precede by many years the onset of clinically important airway obstruction. During the relentless progression of the disease, airway obstruction becomes irreversible due to recurrent respiratory tract infections, which lead to exacerbations of the obstruction and cause increased disability. When the disease is advanced, respiratory tract infections precipitate acute respiratory failure. As the patient progresses into chronic respiratory failure, right-sided heart failure (cor pulmonale) also ensues. In contrast, emphysema is characterized by the loss of elastic recoil of the lungs, which probably precedes the onset of symptoms by many years. Presenting initially with dyspnea on exertion, it increases inexorably without the fluctuations seen in chronic bronchitis. In the terminal stages, the patient is grossly dyspneic at rest and usually succumbs to intercurrent respiratory tract infections. Due to this difference in disease progression, central cyanosis and heart failure are features more common in chronic bronchitis than in emphysema. These features significantly affect the accuracy of pulse oximeter readings.

One of the shortcomings of this study is the lack of consideration of the effects of carboxyhemoglobin, which might affect the analysis because many smokers have higher levels of carboxyhemoglobin. The study is also limited by its small sample size, but it suggests that: (1) the handheld pulse oximeter on its own was suspect in assessing respiratory failure in subjects with COPD; (2) it may help in monitoring trends in patients with hypoxemia established by $\mathrm{ABG}$ analysis; (3) it is not conclusive in diagnosing respiratory failure but is an adjunct to the $\mathrm{ABG}$ analysis; (4) the variability of the readings was greater in subjects with chronic bronchitis than in those with emphysema due to hemodynamic instabilities, which are more frequent with the former subjects.

\section{ACKNOWLEDGMENTS}

We thank Dr G Ramakrishna and Dr T Narayan Rao for reviewing the manuscript.

\section{REFERENCES}

1. Güryay MS, Ceylan E, Günay T, Karaduman S, Bengi F, Parlak I, Ciçek M, Cimrin AH. Can spirometry, pulse oximetry and dyspnea scoring reflect respiratory failure in patients with chronic obstructive pulmonary disease exacerbation? Med Princ Pract 2007;16(5):378-383.

2. Perkins GD, McAuley DF, Giles S, Routledge H, Gao F. Do changes in pulse oximeter oxygen saturation predict equivalent changes in arterial oxygen saturation? Crit Care 2003;7(4):R67.

3. Abrams GA, Sanders MK, Fallon MB. Utility of pulse oximetry in the detection of arterial hypoxemia in liver transplant candidates. Liver Transpl 2002;8(4):391-396.

4. Van de Louw A, Cracco C, Cerf C, Harf A, Duvaldestin P, Lemaire $\mathrm{F}$, Brochard L. Accuracy of pulse oximetry in the intensive care unit. Intensive Care Med 2001;27(10):1606-1613.

5. Vestbo J, Hurd SS, Agustí AG, Jones PW, Vogelmeier C, Anzueto $\mathrm{A}$, et al. Global strategy for the diagnosis, management, and prevention of chronic obstructive pulmonary disease: GOLD executive summary. Am J Respir Crit Care Med 2013;187(4):347-365.

6. Meneely GR, Wyatt JP, Steele JD, Renzetti AD, Harris HW. Chronic bronchitis, asthma, and pulmonary emphysema: a statement by Committee on Diagnostic Standards for Nontuberculous Respiratory Diseases. Am Rev Respir Dis 1962;85(5):762-763.

7. Pistolesi M, Camiciottoli G, Paoletti M, Marmai C, Lavorini F, Meoni E, et al. Identification of a predominant COPD phenotype in clinical practice. Respir Med 2008;102(3):367-376.

8. Confalonieri M, Potena A, Carbone G, Porta RD, Tolley EA, Umberto Meduri G. Acute respiratory failure in patients with severe community-acquired pneumonia. A prospective randomized evaluation of noninvasive ventilation. Am J Respir Crit Care Med 1999; 160(5):1585-1591.

9. Bhattacharya SK, and Sur D. Ethical guidelines for biomedical research on human participants. Ind J Med Res 2007;126(6):587.

10. Bland JM, Altman DC. Statistical methods for assessing agreement between two methods of clinical measurement. Lancet 1986;1(8476): 307-310. 


\section{Pulse Oximetry Overestimates Oxygen Saturation in COPD}

11. Vizza CD, Lynch JP, Ochoa LL, Richardson G, Trulock EP. Right and left ventricular dysfunction in patients with severe pulmonary disease. Chest 1998;113(3):576-583.

12. Lellouche F, Lipes J, L'Her E. Optimal oxygen titration in patients with chronic obstructive pulmonary disease: a role for automated oxygen delivery? Can Respir J 2013;20(4):259261.

13. Nesseler N, Frénel JV, Launey Y, Morcet J, Mallédant Y, Seguin P. Pulse oximetry and high-dose vasopressors: a comparison between forehead reflectance and finger transmission sensors. Intensive Care Med 2012;38(10):1718-1722.

14. Swigris JJ, Zhou X, Wamboldt FS, du Bois R, Keith R, Fischer A, et al. Exercise peripheral oxygen saturation $\left(\mathrm{S}_{\mathrm{pO}_{2}}\right)$ accurately reflects arterial oxygen saturation $\left(\mathrm{S}_{\mathrm{aO}_{2}}\right)$ and predicts mortality in systemic sclerosis. Thorax 2009;64(7):626-630.

15. Tachibana C, Fukada T, Hasegawa R, Satoh K, Furuya Y, Ohe Y. Accuracy of a pulse oximeter during hypoxia. Masui 1996;45(4):479-482.

16. Ibáñez J, Velasco J, Raurich JM. The accuracy of the Biox 3700 pulse oximeter in patients receiving vasoactive therapy. Intensive Care Med 1991;17(8):484-486.

17. Mardirossian G, Schneider RE. Limitations of pulse oximetry. Anesth Prog 1992;39(6):194-196.

18. Schnapp LM, Cohen NH. Pulse oximetry: uses and abuses. Chest 1990;98(5):1244-1250.

19. Field GB. Aspects of applied physiology in chronic bronchitis and emphysema. Aust J Physiother 1973;19(4):125-131.

This article is approved for Continuing Respiratory Care Education credit. For information and to obtain your CRCE

(free to AARC members) visit 